\title{
A QUALITATIVE RESEARCH REGARDING THE ONLINE ADVERTISING FORMATS USED BY ROMANIAN COMPANIES
}

\author{
Acatrinei Carmen, PhD \\ The Bucharest Academy of Economic Studies \\ Email: Carmen.acatrinei@gmail.com
}

(Received June 2015; accepted August 2015)

\begin{abstract}
The present paper offers an in-depth view about the online advertising formats that are used by Romanian companies or digital advertising agencies. The qualitative research based on semi-structured detailed interviews with 12 professionals, took place in Bucharest, in February-March 2015. From the online advertising formats defined by IAB, the Romanian representatives mentioned to promote their organizations or to develop campaigns for their clients by using: search, display, social media, video advertising, affiliate marketing and sponsorship advertising format (advertorials and content sponsorship). The specialists argued about the most relevant and efficient online advertising format that they use. From their personal experience, the professionals were asked to mention which are the elements / attributes that have a significant impact on: search, display, video, social media and mobile advertising campaigns. All the respondents mentioned that their companies use remarketing campaigns. The budget of an online advertising campaign is settled differently among the formats used. The purpose of the paper is to analyze the views of professionals regarding the Romanian online advertising market and this study precedes a quantitative research among Romanian consumers exposed to online advertising campaigns in order to make a comparison between the results obtained in both studies and propose a model of online advertising campaign as close to consumers' wants.
\end{abstract}

Key words: online advertising; qualitative research; online marketing.

J.E.L. CODES: M31; M37.

\section{Introduction}

Since the development and increased use of internet, marketers struggled to catch the user's attention and drive him / her to organization's website in order to attract him / her to buy products / services / join events etc. Over the time, marketers have designed and developed more and more creative online advertising campaigns in order to position as well as possible in their target's minds.

Interactive Advertising Bureau (IAB) encompasses around 650 media companies that sell, distribute and optimize online marketing, and accounts for $86 \%$ of the United States of America's (USA) online advertising market. It is the organization that regulates the online advertising industry and evaluates, makes standards and guides in this domain. IAB's report from 2014 (IAB, 2014, p. 4) confirms that in 
2013, the revenues from online advertising in USA has reached $\$ 42,78$ billion (an increase of $17 \%$ from 2012). The last IAB report (IAB, 2015, p. 4) shows that in 2014 , the revenues from online advertising in USA has reached $\$ 49,5$ billion, determining an increase of $16 \%$ from 2013. In 2014, in Europe, the online advertising market was estimated at 30,7 billion Euro, in comparison with 2013 when it was only 27,4 billion Euro (IAB Europe, 2015, pp. 6, 8). The budgets spent online are getting closer to those spent on television advertising (Figure 1).

Figure 1 Online advertising market in Europe, 2014

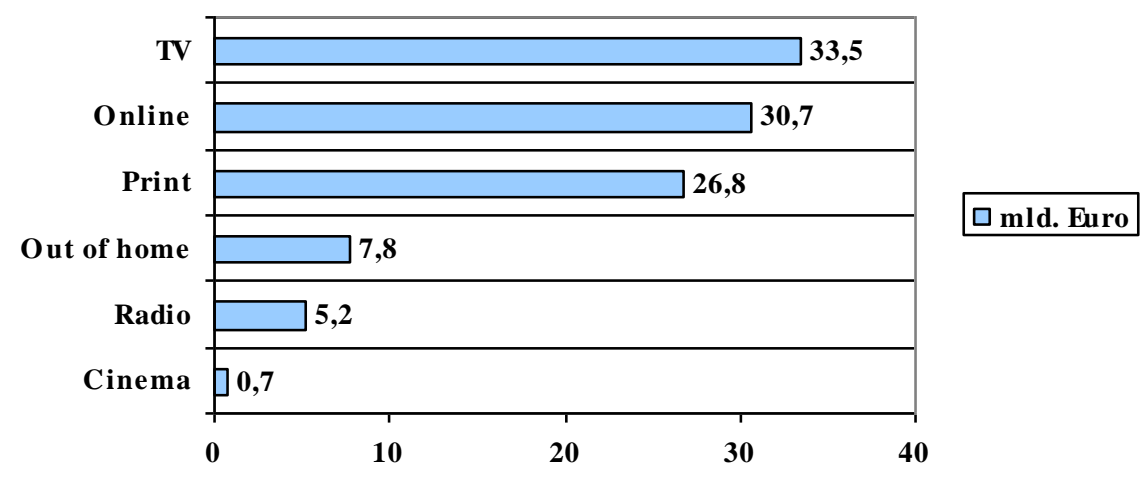

Source: IAB Europe, 2015, p. 13

All European countries have reached an increase in the budgets spent on online advertising and although Romania (33 billion Euro) has surpassed Bulgaria (19 billion Euro) in 2013, the revenues incurred in Bulgaria in 2014 (18,7\%) surpassed Romania (2,3\%), which had the lowest percent increase in the European rank (Figure 2).

The ways by which the consumers are exposed to online advertising are called: online advertising formats (IAB, 2015; IAB Europe, 2015), online advertising channels (Klapdor, 2013; Bundy, 2011; Fishkin, 2009), online promotion techniques (Chaffey et al., 2009, p. 373), types of online advertising (Homburg et al., 2009) or online advertising forms (Kotler et al., 2008), but they all refer to the same thing: measures meant to develop brands and to increase sales using the online environment (Chaffey et al., 2009). In the present paper they are going to be called 'formats' here and after.

The aim of this paper is to offer an in-depth overview about the online advertising formats used by Romanian professionals and to analyze the elements that should be taken into consideration when designing online advertising campaigns. 
Figure 2 Increase rate of online advertising in Europe, 2014 (\%)



Source: IAB Europe, 2015, p. 17

\section{Literature review}

The 10 online advertising formats as defined by IAB (IAB, 2015, pp. 24-25) are: banner advertising - it was called display advertising in last year's IAB report (IAB, 2014, p. 23); sponsorship, email, search, lead generation, classifieds and auctions, rich media, digital video advertising, mobile advertising, social media advertising.

In case of banner advertising, the user is driven to a landing page through a static logo or banner that is inserted in one or more webpages (IAB, 2015, p. 24). With the fall of banner ads usage, from 58\% in 1998, to $21 \%$ in 2003 (Li \& Leckenby, 2007) other online advertising formats have been designed and implemented and were better accepted by the users, for instance video advertising (Reid, 2010). There should be a discussion related to banners, rich media advertising and digital video advertising and the differences between them. Digital video advertising 
refers to advertising that appears at the beginning, during or at the end of a video content watched by a person by using a video player (pre-, mid-, end-roll video ads) and can include banner ads and rich media (also other online advertising formats), as long as they appear in a video player. Rich media includes display ads that have an interactive component, usually done by using flash or java script, it can also be a video that appears in a webpage accessed by the user. In case banner ads or rich media appears while watching a video in a video player, IAB (2015, pp. 24-25) considers them digital video advertising.

The organization may want to sponsor content or personalized experiences, including: sponsorship and / or personalization with own brand of a certain section in the website / email, contests and advergaming, personalized webpages having a topic related to the interests of the organization (IAB, 2015, p. 24). Sponsorship format, including content marketing, refers to the marketing techniques of creating and distributing relevant and valuable content and unlike traditional advertising, it tries to create a conversation between the organization and the reader (Leibtag, 2013, p. 241).

According to IAB (2015, p. 24), online advertising through email refers to the banners, links or sponsorship delivered by newsletters, email marketing campaigns and other commercial communications through email and can be an entire email or just a part of it. This definition included the concept of email marketing campaigns and should not be confused with direct email marketing campaigns which allow the exchange of information between the organization and the consumers in a direct, interactive, personalized manner, stimulating an immediate reaction from the recipients (Veghes, 2003, p. 347). Direct email marketing campaigns and online advertising are two different online marketing tools that marketers can use to develop their businesses in the online environment. Online advertising campaigns by email can include commercial messages sent by email to a database, but they are not based on direct communication with the consumer (this is an essential characteristic of direct email marketing campaigns).

Search advertising includes: paid listings (the paid results that appear at the top or side of search results when specific keywords are searched for, payment is made for clicks incurred on the paid results), contextual search (the links that appear within an article based on the content shown to the reader), paid inclusion (payments made to guarantee a webpage is indexed in search engines) and site optimization (payments made for the optimization of website's appearance in the results returned by search engines) (IAB, 2015, p. 24).

Lead generation refers to payments done for qualified potential customers and is priced on performance basis (for an action wanted by the organization, for a lead or an enquiry) and even though it is not specified in IAB's report $(2015$, p. 24), lead generation includes affiliate marketing. 
Classifieds and auctions refers to payments done to businesses like: online job boards, real estate listings, automotive listings for publishing the products or services the advertiser offers.

Mobile advertising can include all formats presented above as long as they are tailored and delivered through a mobile device (smartphones, tablets).

Social media advertising was introduced for the first time in IAB's 2015 (p. 25) report and includes advertising delivered on any types of devices, but displayed on social networks, social gaming sites or apps.

\section{Methodological notes}

The present paper shows the results obtained from an exploratory qualitative research that had the purpose to study which online advertising formats are used by the Romanian professionals and how are the formats employed in order to promote their organizations or (in case of agencies) their clients. 12 semi-structured detailed interviews, based on a conversation guide (Pop, 2001, p. 86-87; Catoiu et al., 2002, p. 207), with online marketing specialists, most of them being Marketing Managers (or similar management position) at digital agencies from Romania (Godmother, 2Parale (two representatives), Webdigital, White Image, Catalyst, Incandescent Marketing, Brand Conversations, Digital Ink, Leo Burnett Romania, Ogilvy \& Mather Romania) and the Online Division Manager from Gerroma SA. The professionals work in online advertising for 5 to 14 years. The experts were recruited using the snow-ball sampling method; the first four of them were lecturers at the program called Google Online Marketing Academy, where they taught courses of online advertising to students and master students. The program was organized by Google Romania in partnership with the Faculty of Marketing from The Bucharest University of Economic Studies, in three consecutive years, 20122015. They have indicated other online marketing specialists, until 12 professionals have been interviewed. The interviews took place in Bucharest, Romania, in February - March 2015, in Romanian (all the quotes from the interview included below were translated very rigorously into English by the author).

In the present paper only a part of the results obtained from the interviews are being presented, the ones related to the following objectives established:

$O 1$. Identify the online advertising formats that are employed by the interviewed organizations and which format/s is/are considered to be the most efficient and relevant, by the experts.

O2. Determine which elements / attributes are considered, by the interviewed professionals, to produce significant impact for campaigns, for each online advertising format.

O3. Determine whether and why the agencies design remarketing campaigns. 
O4. Determine the respondents' opinions on how the budget dedicated to an online advertising campaign should be split.

\section{Main findings}

The specialists were asked to mention which are the online advertising formats that their organizations use $(\mathrm{Ol})$ and only five of them mentioned only the formats defined by IAB, all the rest have added at least one item which does not belong to the formats defined by IAB $(2015$, p. 24). The online advertising formats that the Romanian digital agencies employ are: display advertising (12/12), search advertising (10/12), social media ads (9/12), video advertising (4/12), affiliate marketing (2/12) and sponsorship (5 respondents mentioned content sponsorship, one respondent mentioned the advertorials). The other items mentioned to be used by their companies are: email marketing (mentioned by five respondents), push and pull marketing, guerilla marketing, SEO (search engine optimization), eCRM (electronic customer relationship management), microsites (each mentioned by one respondent).

It needs to be mentioned that email marketing is an important medium of marketing communication (Ellis-Chadwick \& Doherty, 2012, p. 843), it is an online marketing tool used for conveying short messages that call for recipient's action. Very often within organizations the tools email marketing and newsletters are used as synonyms, but in literature, it is made a clear differentiation between the two of them (Pantea \& Pop, 2010, p. 739). Push and pull are basic promotion mix strategies; push strategy refers to driving the product to the final consumer, while the pull strategy refers to the activities done in order to drive the final consumers to the organization (Kotler \& Armstrong, 2010, p. 442). The respondent who mentioned these strategies, actually referred to search and display advertising in case of pull marketing. Guerrilla marketing is an advertising strategy which refers to using low-cost unconventional means in order to promote a product or a service (De Cram101, 2014). SEO refers to enabling a website to be shown in the results of a search engine, when some key words are introduced. SEO requires informatics knowledge and some technical conditions must be fulfilled in order to optimize the website's appearance in the results (Nursel \& Utku, 2010, p. 488). eCRM represents a system by which organizations can conduct interactive, personalized communications with customers, in order to build and develop long term relationships with them and to improve customer retention rates (Cho \& Fjermestad, 2015, p. 35; Chaturvedi \& Bhatia, 2001, p. 118). The microsite is a smaller website (Fincanon, 2010, p. 114).

In what concerns the efficiency of online advertising formats, almost half of the specialists mentioned that there cannot be named one most efficient format, "there is no silver bullet, because if there was, everybody would use it and it would lose 
its efficiency. Moreover, for each organization there may be a certain advertising channel that performs better than the rest and on the long run, the organization should be used a mix of tools to increase the number of leads generated". Another expert mentioned that "the efficiency of a campaign is measured in reach, conversions and brand favorability - there is no online advertising format that maximizes all three of them". Two of the specialists mentioned that the most efficient format is the one that delivers the best in relation to the objectives settled in the brief / campaign. The professionals who did appoint one online advertising as the most efficient one, have mentioned: search advertising (4/7), display advertising - including remarketing (3/7) and affiliate marketing (2/7).

Only one specialist mentioned that "relevance is relative, it differs from one group to another", all the other respondents mentioned at least one online advertising format that they consider to be more relevant than the others: search advertising (4/11), display advertising (3/11), social media ads (3/11), content sponsorship $(2 / 11)$ and video advertising (1/11).

The professionals had to mention which are the elements / attributes that would to produce a significant impact for campaigns, for each online advertising format (O2). In what concerns search advertising, the text ad should be relevant (6/12) for the keywords (3/12) searched by the user and for his present needs (3/12); it must include only one call-to-action (4/12) and the landing page should be optimized for the keywords used in the campaign (3/12); the message should be short and convincing (3/12) and should include the benefits that can be received (2/12), together with the offer (1/12); it should target correctly (2/12) the audience and it should be "remarkable" (1/12).

In what concerns display advertising, the specialists offered a wide range of responses / elements / attributes. Correct targeting, presence of the offer (benefits / prizes / products / services) according to the needs of the target and the existence of a call-to-action were mentioned by three of the respondents and other elements such as: clear and attractive message, relevant, layout and animated (maximum 3 frames) were mentioned by two experts. It is difficult to propose a "recipe" for designing display ads since there were so many other / different elements mentioned, such as: memorable, creative, attractive, nonintrusive, nonaggressive (usually static banners are less aggressive), no sound, not long, include an innovative element, include: real images, the name of the website, organization's logo and a button. Only one specialist mentioned that "banners do not bring results anymore; there are fewer and fewer people, no matter the target, who click on banners or who watch an animated banner until the end; so they should be rare".

In what concerns video advertising, half of the experts highlighted the importance of the first 5 seconds of the video ad. They mentioned that in these five seconds, the ad should capture the viewer's attention and make him / her curious not to skip 
the ad, creativity and creation matters the most in a video. They also mentioned that the company's logo / brand should also appear / be mentioned in the first seconds, main information and call-to-action should also be provided and a surprise element would increase the chances of the ad to be seen until the end. Concerning the length of the ad, a professional mentioned it should not last longer than one minute, but another specialist said that "if it has a creative idea it can last for an hour". High quality in what concerns image and sound were also mentioned by respondents. Three of the specialists mentioned that targeting is also important in case of video ads. Other elements mentioned were: to be memorable and deliver the wanted message, to be relevant, video can include endorsers, the viral factor should be pursued and organizations should not adapt TV commercials for the online environment.

In what concerns social media advertising, all specialists have designed campaigns on social networks, mostly on Facebook, the other social networks mentioned were: YouTube, LinkedIn, Instagram and G+. A third of the respondents highlighted the fact that when people access social networks they want to relax so the message in the ads should be funny, amusing, entertaining. The image should be familiar and relevant for the user (5/12) and it should not repeat the text of the message, but to be complementary; the text should also include a call-to-action $(4 / 12)$.

When it comes to mobile advertising, only 10 of the respondents have designed campaigns for their organizations or their clients. Most of the specialists insisted on the optimization of the ad for mobile in terms of responsiveness and adaptation. The call-to-action, good targeting and easiness in reading the message were also mentioned by the professionals. Three of the respondents concluded that mobile advertising works the best in case of businesses where the time to make a decision is rather small or the necessity is rather urgent (e.g. auto towing, unlocking blocked doors, medical emergencies for humans and pets, restaurants in the area).

When asked about the other online advertising formats, ten of the respondents have designed advertorials, nine of them have used affiliate marketing, only one has used advergaming, but just for testing; and in what concerns email advertising, the majority of the respondents first thought about email marketing campaigns when the question was addressed.

All the professionals have stated that they implement remarketing campaigns (O3). The purpose for the remarketing campaigns were somewhat different, the majority mentioned that they use remarketing for selling, to increase the conversion rate $(8 / 12)$, a quarter of the professionals design such campaigns for reminding users to complete an action desired by the organizations and for raising awareness branding purposes. 
In terms of splitting the budget among different online advertising formats (O4), the answers were very different, but most of them included the statement: "it depends on the type of campaign" and only two respondents did not answer the question, for privacy reasons. One of the professionals would allocate budgets in this order: "Google AdWords (Search, Remarketing, Display, YouTube), Facebook, affiliate marketing", similar to this opinion, another expert would allocate $75 \%$ of the budget to Google AdWords and Google Display Network, and the rest to Facebook and eCRM. The other percents stated by the specialists were either: 5050\% (search and Facebook vs. display), 80-20\% (search vs. display), 20-80\% (display vs. search). In their answers, none of the 10 experts mentioned specifically to allocate budget to video advertising, one opinion that might include this format was: "it is calculated based on the business objectives and the stage each business finds itself in, but usually, pay-per-click budget is larger than the other online advertising budgets". To sum up, one professional's statement is eloquent: "I think the mix of instruments depends on the type of business and campaign's objective; there is no universal formula!".

\section{Conclusions}

Based on the literature studied and after interviewing the Romanian professionals, the author would like to propose the following eight online advertising formats, used by Romanian organizations:

Search advertising - is the advertising format that appears as a result of a search done by a user who introduces search terms and expects to find relevant links that would satisfy his searching needs. Search advertising appears mostly on search engines (e.g. Google, Yahoo, Bing etc.), but it is not limited to them (e.g. YouTube, OLX.ro etc.)

Display advertising - is the advertising format that appears on different websites, either in a static format, either dynamic / animated or interactive, having different shapes and dimensions, can include pictures / logos / short videos. Examples of display advertising are: banners, buttons, sidebars / skyscrapers, pop-ups / popunder, page peel ads, interstitials etc. (Pantea \& Veghes, 2009, p. 275; Burns \& Lutz, 2006).

Video advertising - includes any type of advertising that appears either before, during or at the end of a movie played in an online video player; and it is either a video, text or display.

Social media advertising - refers to the advertising delivered on social platforms (e.g. Facebook, LinkedIn, G+, Instagram, Twitter, Pinterest etc.) and can include text and a representative image. 
Email advertising - is the online advertising format that appears in a user's email account, being either text (usually above the emails received) or image (usually on the right side of the screen).

Sponsorship - refer to content / advertorials (articles that promote different products or services that have been sponsored to be written by the authors) or advergaming (advertising delivered in online games).

Lead generation / Affiliate marketing - implies the existence of a platform that offers interaction facilities between organizations / advertisers, which are willing to offer part of their profit to persons / affiliates who would promote the organizations (through the tools the company accepts).

Mobile advertising - encompasses all previous online advertising formats mentioned briefly above, with the sole condition to be delivered on a mobile device (either smartphone, tablet etc.).

The semi-structured interviews included not only the aspects mentioned above, but also several questions related to online advertising, elements that contribute to a successful online advertising campaign, the services offered by the Romanian companies, the sector/s of activity where online advertising campaigns apply the best and the future of online advertising in Romania as seen by the experts. The analysis of those questions is the subject of a different scientific paper, entitled: "Remarks about Online Advertising - A Qualitative Research among Romanian Professionals". It must be emphasized that the interviews were taken in Romanian, but the author noted a great amount of English words used by the professionals, when providing their answers.

In what concerns the online advertising formats, the display format was the one that received the most different answers possible, so it would be difficult to propose a model covering all the aspects mentioned. Also, the question related to the budget, was also difficult to analyze due to the wide range of responses received.

Future directions of research may include a survey among Romanian consumers with the purpose of identifying their view on how the companies are employing online advertising and find similarities / dissimilarities between their point of view and the professionals' point of view. A research regarding the level of revenues brought by the formats proposed by the author, at the level or Romania would also be helpful.

\section{Acknowledgements}

This work was cofinanced from the European Social Fund through Sectorial Operational Programme Human Resources Development 2007-2013, project number POSDRU/159/1.5/S/134197 „Performance and excellence in doctoral and postdoctoral research in Romanian economics science domain”. 


\section{References}

1. Bundy, S., (2011). The 10 Internet Marketing Channels Crucial to Your Success in 2011, Retrieved from: http://www.revenews.com/search-enginemarketing/ the-10-internet-marketing-channels-crucial-to-your-success-in2011/.

2. Burns, K.S., \& Lutz, R.J. (2006). The function of format: Consumer responses to six online advertising formats, Journal of Advertising, 35, 53-63.

3. Catoiu, I. (coord.), Balan, C., Popescu, I.C., Orzan, G., Veghes, C., Danetiu, T. \& Vranceanu, D., (2002). Cercetari de marketing. Bucharest: Uranus.

4. Chaffey, D., Ellis-Chadwick, F., Mayer, R. \& Johnston, K. (2009). Internet marketing, ed. 4, Essex: Pearson Education.

5. Chaturvedi, K., \& Bhatia, A.B., (2001). eCRM: Deriving value of customer relationship, pp. 117-128, in eds. Sheth, J.N., Parvatiyar, A., \& Shainesh, G., Customer Relationship Management - Emerging Concepts, Tools and Applications, New Delhi: Tata McGraw Hill.

6. Cho, Y., \& Fjermestad, J., (2015). Using electronic customer relationship management to maximize / minimize customer satisfaction / dissatisfaction, pp. 34-52, in eds. Fjermestad, J. \& Robertson, N.C.Jr., Electronic Customer Relationship Management, New York: Routledge.

7. De Cram101, (2014). Just the Facts. Framework for Marketing Management $4^{\text {th }}$ ed. Study guide, Available: https://goo.gl/RvQarX, accessed May 2015.

8. Ellis-Chadwick, F., \& Doherty, N.F., (2012). Web advertising: The role of email marketing, Journal of Business Research, 65, 843-848.

9. Fincanon, J., (2010) Flash Advertising: Flash platform development of microsites, advergames and branded applications, New York: Focal Press.

10. Fishkin, R., (2009). A Checklist to Choose Which Internet Marketing Channel is Right for Your Business, Retrieved from: https://moz.com/blog/a-checklistto-choose-which-internet-marketing-channel-is-right-for-your-business.

11. Homburg, C., Kuester, S. \& Krohmer, H., (2009). Marketing management: A contemporary perspective, Berkshire: McGraw-Hill.

12. IAB (2014) IAB internet advertising revenue report 2013 full year results, Retrieved: http://www.iab.net/media/file/IAB_Internet_Advertising_Revenue _Report_FY_2013.pdf, accessed April 2015.

13. IAB (2015). IAB internet advertising revenue report 2014 full year results, Retrieved: http://www.iab.net/media/file/IAB_Internet_Advertising_Revenue Report FY 20142.pdf, accessed May 2015.

14. IAB Europe (2015) IAB Europe AdEx Benchmark 2014, disponibil la adresa: http://goo.gl/q15P72, accessed April 2015. 
15. Klapdor, S., (2013). Effectiveness of online marketing campaigns. An investigation into online multichannel and search engine advertising, Munich: Springer Gabler.

16. Kotler, P., \& Armstrong, G., (2010). Principles of marketing, $13^{\text {th }}$ ed., New Jersey: Pearson.

17. Kotler, P., Armstrong, G., Wong, V. \& Saunders, J., (2008). Principles of marketing, ed. 5, Essex: Pearson Education.

18. Leibtag, A., (2013). The Digital Crown: Winning at Content on the Web, Boston: Morgan Kaufmann.

19. Li, H., \& Leckenby, J.D., (2007). Examining the effectiveness of Internet advertising formats. Internet advertising: Theory and research, ed. D.W. Schumann and E. Thorson, 203-224. Jersey: Lawrence Erlbaum Associates, Inc.

20. Nursel, Y., \& Utku, K., (2010). What is search engine optimization: SEO?, Procedia Social and Behavioral Sciences, 9, 487-493.

21. Pantea, C., \& Pop, N.Al., (2010). Email marketing campaigns: the easiest path from organizations to consumers - an exploratory assessment, The Annals of the University of Oradea, Economic Sciences Fascicle - TOM XIX, 737-742, ISSN 1582-5450.

22. Pantea, C., \& Veghes, C., (2009). The development of online advertising on the Romanian Market: from conceptual basics to the operational drivers, Proceedings of the 16th International Economic Conference on "Industrial Revolutions, from the Globalization and Post-Globalization Perspective", Section Marketing, Commerce and Tourism and a New Paradigm of Change, Sibiu, Romania, Sibiu, Romania, 7-8 May 2009, pp. 273-280,

23. Pop, N.Al., (2001). Marketing. Bucharest: Didactica si Pedagogica.

24. Reid, A. (2010). Online video ad formats. Campaign, 24. Retrieved from http://search.proquest.com/docview/807661648?accountid=15533.

25. Veghes, C., (2003). Marketing direct, Bucharest: Uranus. 